\title{
Association of Maternal Serum 25-Hydroxyvitamin D Concentrations with Risk of Gestational Anemia
}

\author{
Yingdi Yuan ${ }^{a, b}$ Zhiyong Cai ${ }^{b}$ YaoYao Daic ${ }^{c}$ Qin Hong ${ }^{d, e} \quad$ Xingyun Wang ${ }^{b}$ \\ Lijun Zhu $^{\mathrm{b}}$ Pengfei Xu ${ }^{\mathrm{b}}$ Lianghui You ${ }^{\mathrm{b}} \quad$ Xing Wang $^{\mathrm{b}} \quad$ Chenbo Jib,d,e \\ Juan Wen ${ }^{\mathrm{b}, \mathrm{d}, \mathrm{e}} \quad$ Xirong Guo $\mathrm{b}^{\mathrm{b}, \mathrm{d}, \mathrm{e}}$
}

aThe First People's Hospital of Lianyungang, Xuzhou Medical University Affiliated Hospital of

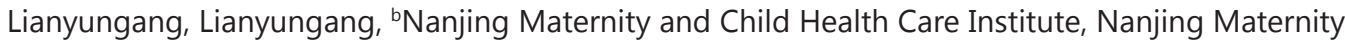
and Child Health Care Hospital, Obstetrics and Gynecology Hospital Affiliated to Nanjing Medical University, Nanjing, 'Nantong Center for Disease Control and Prevention, Nantong, dDepartment of Children Health Care, Nanjing Maternity and Child Health Care Hospital, Obstetrics and Gynecology Hospital Affiliated to Nanjing Medical University, Nanjing, eState key Laboratory of Reproductive Medicine, Nanjing Maternity and Child Health Care Hospital, Obstetrics and Gynecology Hospital Affiliated to Nanjing Medical University, Nanjing, China

\section{Key Words}

Vitamin $\mathrm{D} \cdot 25(\mathrm{OH}) \mathrm{D} \cdot$ Anemia

\begin{abstract}
Background/Aims: Vitamin D deficiency has been shown to be associated with a greater prevalence of anemia in various healthy and diseased populations by a great deal of observational studies. However, less work has been done to explore this association in pregnant women. The aim of this study was to evaluate the association between maternal serum 25 -hydroxyvitamin $\mathrm{D}[25(\mathrm{OH}) \mathrm{D}]$ concentrations and risk of gestational anemia in a large, nested case-control study. Methods: The serum 25(OH)D concentrations was measured by enzyme immunoassay in 775 pregnant women affected with anemia and 1550 controls. Logistic regression analysis was conducted to assess the association of $25(\mathrm{OH}) \mathrm{D}$ concentrations with risk of gestational anemia. Results: We found the 25(OH)D concentrations was significantly lower in women affected with anemia than in controls. Logistic regression analyses showed that women with 25(OH)D concentrations < $25.0 \mathrm{nmol} / \mathrm{L}$, from 25.0 to $37.4 \mathrm{nmol} / \mathrm{L}$ and from 37.5 to $49.9 \mathrm{nmol} / \mathrm{L}$ all had increased risk of anemia when compared with women with concentrations from 50.0 to $74.9 \mathrm{nmol} / \mathrm{L}$. And the risk of anemia was significantly increased with the decreasing concentrations of the serum $25(\mathrm{OH}) \mathrm{D}$ in a dose-dependent manner $(P$ for trend $=0.012)$. For women with concentrations $<50.0 \mathrm{nmol} / \mathrm{L}$, they had an $80 \%$ increase in anemia risk $(95 \% \mathrm{CI}$ $=1.45-2.25$ ) after adjustment for confounders. We also observed a nonlinear relationship between the serum 25(OH)D and anemia, with a threshold for 25(OH)D of $50.0 \mathrm{nmol} / \mathrm{L}$ existed for anemia. Conclusion: Maternal serum 25(OH)D $<50.0 \mathrm{nmol} / \mathrm{L}$ may be a risk factor for gestational anemia, and it should be monitored for the high-risk pregnant women.

Y. Yuan, Z. Cai and Y. Dai contributed equally to this work.

Juan Wen

and Xirong Guo

Nanjing Maternity and Child Health Care Institute, Department of Children Health Care and State key Laboratory of Reproductive Medicine, Nanjing, (China)

E-Mailwenj2010@gmail.com and xrguo@njmu.edu.cn
\end{abstract}




\section{Cellular Physiology Cell Physiol Biochem 2017;43:1526-1532 \begin{tabular}{l|l|l} 
and Biochemistry Published online: October 16, 2017 & $\begin{array}{l}\text { (c) } 2017 \text { The Author(s). Published by S. Karger AG, Basel } \\
\text { www.karger.com/cpb }\end{array}$ \\
\hline
\end{tabular} \\ Yuan et al.: Maternal 25(OH)D Levels and Gestational Anemia}

\section{Introduction}

Anemia is characterized by a decrease in concentration of red blood cells or haemoglobin, resulting in impaired oxygen transport throughout the body, which is a major global health concern. About 1.62 billion people are anemic in the world, and anemia is more prevalent in pregnant women. An estimated $50 \%$ of pregnant women have anemia in developing countries, compared with 12\%-25\% in developed countries [1]. Gestational anemia has been associated with an increased risk of intrauterine growth restriction, premature birth, low birth weight, postnatal depression, and maternal morbidity and mortality [2, 3]. It is known that a wide variety of causes could induce anemia, such as iron deficiency, malabsorption, hemolysis, chronic disease or a combination of these [4, 5]. In recent years, an association between anemia and vitamin $\mathrm{D}$ has emerged.

Vitamin D deficiency is also an important issue in public heath as it is implicated in a wide range of physiological processes beyond bone metabolism. The deficiency of vitamin $\mathrm{D}$ is widespread among the general population and is highly prevalent in pregnant women [6-10]. Vitamin D deficiency has been shown to be associated with lower hemoglobin (Hgb) levels and a greater prevalence of anemia in various healthy and diseased populations by a great deal of observational studies [11-15]. Furthermore, retrospective cohort studies in adults with chronic kidney disease have demonstrated that vitamin D supplementation may improve anemia management [16]. However, less work has been done to explore this association in pregnant women.

25-hydroxyvitamin D [25(OH)D], a main indicator of vitamin D status, is used to define vitamin $\mathrm{D}$ deficiency in most studies. In our previous large cohort study, we found women with $25(\mathrm{OH}) \mathrm{D}<50.0 \mathrm{nmol} / \mathrm{L}$ had increased risk of gestational anemia in both univariate and multivariate logistic regression analysis, when compared with women with 25(OH)D concentrations from 50.0 to $74.9 \mathrm{nmol} / \mathrm{L}$ [17]. To further evaluate the relationship of maternal vitamin D deficiency and risk of gestational anemia, we performed a nested case-control study in 1:2 ratio, including 775 pregnant women affected with anemia and 1550 controls. Furthermore, we evaluated the threshold of $25(\mathrm{OH}) \mathrm{D}$ concentrations for gestational anemia.

\section{Materials and Methods}

This study was approved by the institutional review board of Nanjing Maternity and Child Health Care Institute, and the methods were carried out in accordance with the approved guidelines. This trial is registered at ClinicalTrials.gov with clinical trial identifier number NCT02236221.

\section{Participants and study design}

We carried out a nested case-control study based on a cohort of 4718 women [17]. The women who had participated in second- and third-trimester pregnancy complications screening at Obstetrics and Gynecology Hospital Affiliated to Nanjing Medical University, between March 2012 and February 2015, were included. Fasting venous blood was drawn for routine multi-index detecting, and serum aliquot was stored at $-80^{\circ} \mathrm{C}$. Maternal information for serum samples were derived from the laboratory databases and the information about anemia were obtained via electronic medical record collection and information extraction. The extracted variables included maternal age (in year), birthplace (Jiangsu province or other provinces), intrapartum body mass index (BMI) $\left(\mathrm{kg} / \mathrm{m}^{2}\right)$, parity (nulliparae or multiparae), menarche age (in year), menstrual cycle (21-35 days, 36 days or irregularity), abnormal pregnancy history (no or yes), sampling trimester (second or third), and sampling season [Northern Hemisphere: spring (March to May), summer (June to August), autumn (September to November) and winter (December to February)]. The pregnancy women with previously diagnosed diabetes (pregestational or gestational) or hypertension (chronic or pregnancy), kidney disease, uterine fibroids, multiple gestation or any other significant preexisting chronic medical disease were excluded.

From the total cohort of 4718 women, 775 pregnant women affected with anemia (hemoglobin $<100$ $\mathrm{g} / \mathrm{L}$ ) and had met all above inclusion and exclusion criteria. These cases were matched by maternal age and 


\section{Cellular Physiology Cell Physiol Biochem 2017;43:1526-1532 \begin{tabular}{ll|l} 
and Biochemistry Published online: October 16, 2017 & $\begin{array}{l}\text { C } 2017 \text { The Author(s). Published by S. Karger AG, Basel } \\
\text { www.karger.com/cpb }\end{array}$ \\
\hline
\end{tabular} \\ Yuan et al.: Maternal 25(OH)D Levels and Gestational Anemia}

birthplace, in 1:2 ratio, to a random computer-generated referent group of 1550 controls (hemoglobin $\geq 100$ $\mathrm{g} / \mathrm{L}$ ) using the same inclusion and exclusion criteria.

\section{Vitamin D measurement}

Maternal serum 25(OH)D concentrations was measured by using an in vitro diagnostic enzyme immunoassay kit OCTEIA 25-Hydroxy Vitamin D (Immunodiagnostic Systems, Boldon, United Kingdom) according to the manufacturer's instructions. The reported analytic sensitivity of the immunoassay was 6.8$380 \mathrm{nmol} / \mathrm{L}$. Commonly used cutoffs to define 25(OH)D status were assigned at 25.0, 37.5, 50.0 and 75.0 $\mathrm{nmol} / \mathrm{L}[17]$.

\section{Statistical analysis}

Differences of maternal characteristics and 25(OH)D serum concentrations between pregnant women affected with anemia and controls were calculated by the Student's $t$-test (for continuous variables), $\chi^{2}$ test (for categorical variables) and Mann-Whitney test (for 25(OH)D concentrations). The relationship between $25(\mathrm{OH}) \mathrm{D}$ concentrations and the risk of gestational anemia was explored by the smoothing plot. Logistic regression analysis were performed to assess the crude and adjusted association between 25(OH)D concentrations $(<25.0,25.0-37.4,37.5-49.9,<50.0,>75.0 \mathrm{nmol} / \mathrm{L} \mathrm{vs.} \mathrm{50.0-74.9} \mathrm{nmol} / \mathrm{L})$ and anemia risk by computing odds ratios (OR) and their $95 \%$ confidence intervals (CIs). In the multivariate regression analysis, maternal age, birthplace, intrapartum BMI, parity, menarche age, menstrual cycle, abnormal pregnancy history, sampling trimester and sampling season were taken into account. The $\chi^{2}$-based Q test was applied to test the heterogeneity of associations between subgroups. All the above statistical analyses were performed with R software (version 2.13.0), and $P \leq 0.05$ in a two-sided test was considered statistically significant.

\section{Results}

We successfully analyzed serum 25(OH)D concentrations from all 2325 samples (775 pregnant women affected with anemia and 1550 controls). The selected characteristics of the 2325 women are summarized in Table 1 . There were no significant differences in the distribution of maternal age, birthplace, intrapartum BMI, parity, menarche age, menstrual cycle, abnormal pregnancy history, sampling trimester and sampling season between the two matched groups (all $P>0.05)$. Maternal serum 25(OH)D concentrations was significantly lower in women affected with anemia [Median (IQR), women affected with

Table 1. Maternal characteristics and serum 25(OH)D concentration between cases and controls

\begin{tabular}{|c|c|c|c|}
\hline Maternal characteristics & $\begin{array}{l}\text { Gestational anemia } \\
(\mathrm{n}=775)\end{array}$ & $\begin{array}{c}\text { Controls } \\
(n=1550)\end{array}$ & $\mathrm{P} b$ \\
\hline Maternal age (years) a & $28.9 \pm 3.5$ & $29.0 \pm 3.2$ & 0.661 \\
\hline Birthplace of Jiangsu province [n (\%)] & $737(95.1)$ & $1485(95.8)$ & 0.433 \\
\hline Intrapartum BMI $\left(\mathrm{kg} / \mathrm{m}^{2}\right)^{\text {a }}$ & $26.9 \pm 3.1$ & $26.9 \pm 3.2$ & 0.667 \\
\hline Nulliparae [n (\%)] & 720 (92.9) & $1438(92.8)$ & 0.910 \\
\hline Menarche age (years) a & $13.7 \pm 1.2$ & $13.7 \pm 1.2$ & 0.222 \\
\hline Long (36 ) or irregular menstrual cycle $[\mathrm{n}(\%)]$ & $66(8.5)$ & $171(11.0)$ & 0.059 \\
\hline Having abnormal pregnancy history [n (\%)] & $109(14.1)$ & $228(14.7)$ & 0.677 \\
\hline $\begin{array}{l}\text { Sampling in second trimester } \\
{[\mathrm{n}(\%)]}\end{array}$ & $289(37.3)$ & $612(39.5)$ & 0.306 \\
\hline Sampling season $[\mathrm{n}(\%)]$ & & & 0.888 \\
\hline Spring & $196(25.3)$ & $386(24.9)$ & \\
\hline Summer & 245 (31.6) & $511(33.0)$ & \\
\hline Autumn & $173(22.3)$ & $348(22.5)$ & \\
\hline Winter & $161(20.8)$ & 305 (19.7) & \\
\hline $25(\mathrm{OH}) \mathrm{D}(\mathrm{nmol} / \mathrm{L}) \mathrm{c}$ & $39.9(33.4,51.4)$ & $44.3(35.8,58.9)$ & $<0.001$ \\
\hline $25(\mathrm{OH}) \mathrm{D}[\mathrm{n}(\%)]$ & & & $<0.001$ \\
\hline$<25.0 \mathrm{nmol} / \mathrm{L}$ & $27(3.5)$ & $31(2.0)$ & \\
\hline $25.0-37.4 \mathrm{nmol} / \mathrm{L}$ & 278 (35.9) & $443(28.6)$ & \\
\hline $37.5-49.9 \mathrm{nmol} / \mathrm{L}$ & 259 (33.4) & $468(30.2)$ & \\
\hline $50.0-74.9 \mathrm{nmol} / \mathrm{L}$ & $141(18.2)$ & $425(27.4)$ & \\
\hline$>75 \mathrm{nmol} / \mathrm{L}$ & $70(9.0)$ & $183(11.8)$ & \\
\hline
\end{tabular}




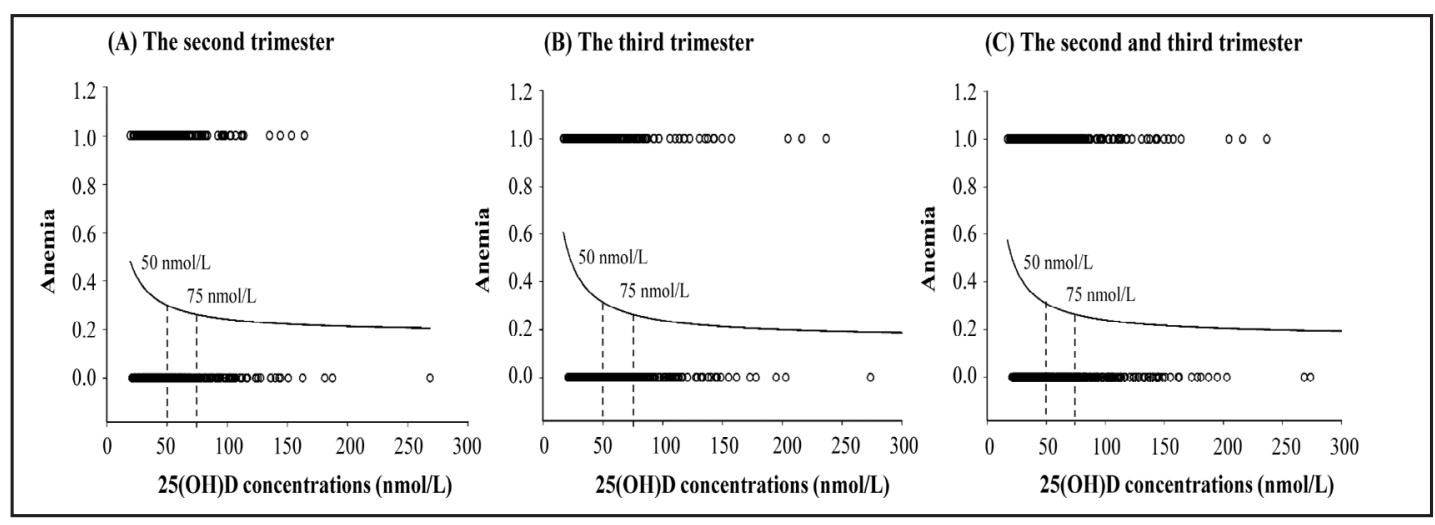

Fig. 1. The relationship between maternal $25(\mathrm{OH}) \mathrm{D}$ and gestational anemia. A nonlinear relationship between the serum 25(OH)D and gestational anemia was observed. (A) For women in the second trimester; (B) For women in the third trimester; (C) For all the women. 25(OH)D, 25-hydroxyvitamin D.

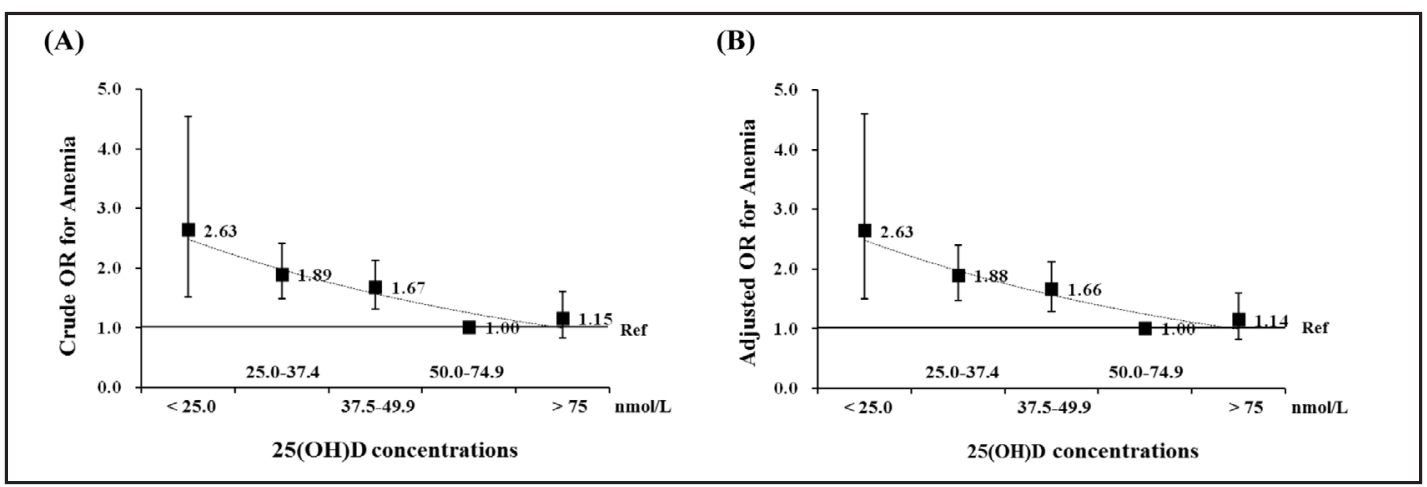

Fig. 2. The crude and adjusted odds ratios (OR) of maternal 25(OH)D concentrations for gestational anemia.

anemia vs. controls: $39.9(33.4,51.4)$ vs. $44.3(35.8,58.9) \mathrm{nmol} / \mathrm{L}, P<0.001]$. Among women affected with anemia, $72.8 \%$ of women had serum concentrations $<50.0 \mathrm{nmol} / \mathrm{L} \mathrm{compared}$ with $60.8 \%$ of women in the controls (Table 1). As shown in Fig. 1, there was a nonlinear relationship between the serum 25(OH)D and anemia, with a threshold for 25(OH)D of 50.0 $\mathrm{nmol} / \mathrm{L}$ existed for anemia. When the 25(OH)D concentrations reached $50.0 \mathrm{nmol} / \mathrm{L}$, the prevalence of gestational anemia plateaued.

Logistic regression analyses showed that women with 25(OH)D concentrations $<25.0$ $\mathrm{nmol} / \mathrm{L}$, from 25.0 to $37.4 \mathrm{nmol} / \mathrm{L}$ and from 37.5 to $49.9 \mathrm{nmol} / \mathrm{L}$ all had increased risk of gestational anemia when compared with women with concentrations from 50.0 to 74.9 nmol/L (Table 2. and Fig. 2). And the risk of gestational anemia was significantly increased with the decreasing concentrations of the serum 25(OH)D in a dose-dependent manner $(P$ for trend $=0.012)$. For women with concentrations $<50.0 \mathrm{nmol} / \mathrm{L}$, they had an $80 \%$ increase in anemia risk (95\% CI $=1.45-2.25)$ after adjustment for confounders (Table 2). The association of the 25(OH)D concentrations with risk of gestational anemia were also evaluated by stratifying on maternal age, intrapartum BMI, parity, menarche age, menstrual cycle, abnormal pregnancy history, sampling trimester and sampling season (Table 2). Similar association strengths were shown between most subgroups ( $P>0.05$ for heterogeneity test).

\section{Discussion}

In this large nested case-control study conducted on gestational anemia, we found maternal serum 25(OH)D concentrations was significantly lower in women affected with 
anemia. For women with concentrations < $50.0 \mathrm{nmol} / \mathrm{L}$, they had an $80 \%$ increase in anemia risk, when compared with women with 25(OH)D from 50.0 to $74.9 \mathrm{nmol} / \mathrm{L}$. We also observed a threshold for $25(\mathrm{OH}) \mathrm{D}$ of $50.0 \mathrm{nmol} / \mathrm{L}$ existed for gestational anemia. Further studies are warranted to validate and extend our findings. In general, our results suggested that maternal serum $25(\mathrm{OH})$ $\mathrm{D}<50.0 \mathrm{nmol} / \mathrm{L}$ may be a risk factor for anemia, and it should be monitored for the high-risk pregnant women.

Our results are in line with recent studies suggesting a strong association of low 25(OH)D with anemia risk in various healthy and diseased populations [11-15]. In a meta-analysis including seven studies involving 5183 participants, the outcomes showed that vitamin D deficiency increased the risk of developing anemia [18]. Bener et al. and Thomas et al. both reported that maternal vitamin D deficiency in pregnancy was significantly associated with elevated risk for anemia $[19,20]$. There are several possible mechanisms to explain the relationship between vitamin D deficiency and anemia. Calcitriol, the active form of vitamin D, could up-regulate the ex-

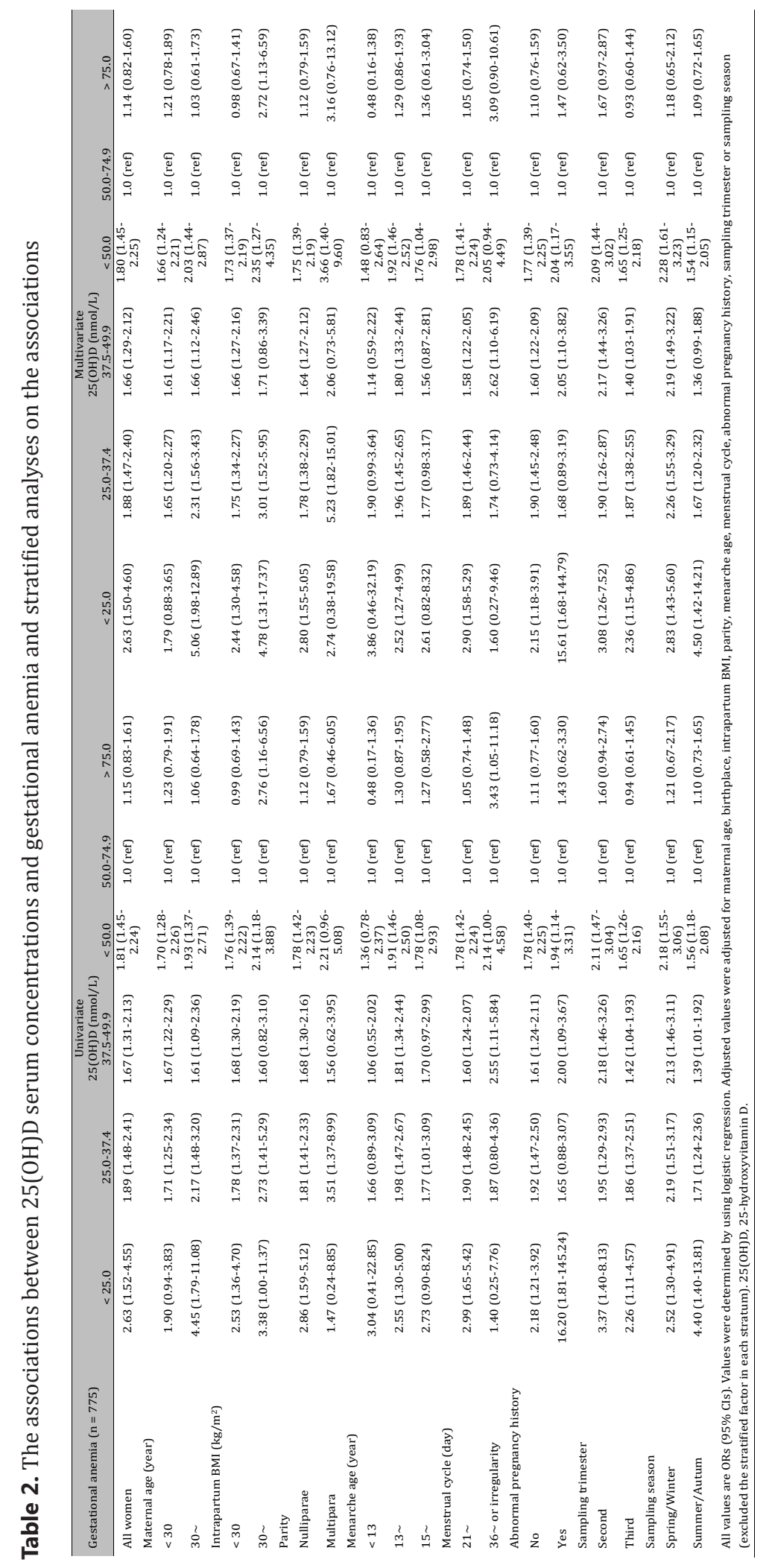
pression of the erythropoietin receptor on erythroid progenitor cells, and may have a proliferative effect on erythroid burst forming units, which is synergistic with erythropoietin. There are data to show vitamin D deficiency result- 
ing in decreased calcitriol production in the bone marrow may limit erythropoiesis [21-23]. Calcitriol also play an important role in the immune function regulation by suppressing the pro-inflammatory cytokines expression [24]. This immunomodulatory effect may be central to its role in preventing anemia. Perlstein et al. found a strong association between vitamin D deficiency and anemia of inflammation compared with both subjects with other anemia subtypes and non-anemic subjects [14]. Besides, hepcidin, a systemic iron-regulatory hormone, was shown to be regulated by iron requirements of erythroid precursors for hemoglobin synthesis, and may be associated with anemia [25,26]. Vitamin D deficiency may upregulate hepcidin, thus promote the decrease of hemoglobin and contribute to anemia [27]. Further studies to deeply explore the possible mechanisms are still warranted.

In this study, the prospective data collection, a relatively large sample size, random sampling and blinded analysis, and statistical adjustment provided sufficient statistical power and convincing data. There are also some limitations to this study. This is a crosssectional study, and thus it is not possible to determine a causal relationship between vitamin D deficiency and anemia. And we did not have data on iron deficiency, Hgb levels, plasma erythropoietin and reticulocyte count, so we could not analyze the relation among vitamin $\mathrm{D}$ and these markers. As our subjects were Chinese pregnant women, it is not clear whether we can extend our results to the other populations. Further prospective studies considering above potential confounders and incorporating diverse populations with long-term effects are warranted, which would have important implications for public health policy. Despite all this, our study has provided robust epidemiological evidence that low serum 25(OH)D in pregnant women was significantly associated with increased risk of gestational anemia. The findings suggested that vitamin D supplements in pregnancy should be encouraged to prevent gestational anemia.

\section{Acknowledgements}

This work was supported in part by the National Key Basic Research Program of China (2013CB530604), the Key project of the National Natural Science Foundation of China (81330067), the National Natural Science Foundation of China (81270928, 81200642, 81301173, 81300683, 81600685), the Natural Science Foundation of Jiangsu Province (BK20160141), and the Medical Science and technology development Foundation of Nanjing Department of Health (YKK16201).

J.W and X.G designed the study. Y.Y, Z.C, Y.D, Q.H, X.W, L.Z, P.X, L.Y and X.W collected the data. J.W, C.J and X.G conducted the statistical analysis and interpretation. Y.Y and Z.C wrote the report. J.W and X.G revised the report. All the authors reviewed the report and approved the final version.

\section{Disclosure Statement}

The authors declare no conflict of interest.

\section{References}

1 McLean E, Cogswell M, Egli I, Wojdyla D, de Benoist B: Worldwide prevalence of anaemia, who vitamin and mineral nutrition information system, 1993-2005. Public Health Nutr 2009;12:444-454.

-2 Beard JL, Hendricks MK, Perez EM, Murray-Kolb LE, Berg A, Vernon-Feagans L, Irlam J, Isaacs W, Sive A, Tomlinson M: Maternal iron deficiency anemia affects postpartum emotions and cognition. J Nutr 2005;135:267-272.

3 Brabin BJ, Hakimi M, Pelletier D: An analysis of anemia and pregnancy-related maternal mortality. J Nutr 2001;131:604S-614S.

4 Weiss G, Goodnough LT: Anemia of chronic disease. N Engl J Med 2005;352:1011-1023.

-5 Gasche C, Lomer MC, Cavill I, Weiss G: Iron, anaemia, and inflammatory bowel diseases. Gut 2004;53:11901197. 


\section{Cellular Physiology Cell Physiol Biochem 2017;43:1526-1532 \begin{tabular}{l|l|l} 
and Biochemistry Published online: October 16, 2017 & $\begin{array}{l}\text { C) } 2017 \text { The Author(s). Published by S. Karger AG, Basel } \\
\text { www.karger.com/cpb }\end{array}$ \\
\hline
\end{tabular}

6 Cashman KD, Dowling KG, Skrabakova Z, Gonzalez-Gross M, Valtuena J, De Henauw S, Moreno L, Damsgaard CT, Michaelsen KF, Molgaard C, Jorde R, Grimnes G, Moschonis G, Mavrogianni C, Manios Y, Thamm M, Mensink GB, Rabenberg M, Busch MA, Cox L, Meadows S, Goldberg G, Prentice A, Dekker JM, Nijpels G, Pilz S, Swart KM, van Schoor NM, Lips P, Eiriksdottir G, Gudnason V, Cotch MF, Koskinen S, Lamberg-Allardt C, Durazo-Arvizu RA, Sempos CT, Kiely M: Vitamin d deficiency in europe: Pandemic? Am J Clin Nutr 2016;103:1033-1044.

7 Yuan Y, Liu H, Ji C, Guo X, Hu L, Wen J, Cai M: Association of maternal serum 25-hydroxyvitamin $\mathrm{d}$ concentrations in second trimester with delivery mode in a Chinese population. Int J Med Sci 2017;14:1008-1014.

-8 Grzegorzewska AE, Izdebska A, Niepolski L, Warchol W, Jagodzinski PP: Self-reported physical activity, quality of life, and psychological status in relation to plasma 25-hydroxyvitamin d concentration in patients treated with hemodialysis. Kidney Blood Press Res 2016;41:886-900.

-9 Zhang H, Zhang H, Wen X, Zhang Y, Wei X, Liu T: Vitamin d deficiency and increased risk of bladder carcinoma: A meta-analysis. Cell Physiol Biochem 2015;37:1686-1692.

10 Wang W, Li G, He X, Gao J, Wang R, Wang Y, Zhao W: Serum 25-hydroxyvitamin d levels and prognosis in hematological malignancies: A systematic review and meta-analysis. Cell Physiol Biochem 2015;35:19992005.

11 Smith EM, Alvarez JA, Martin GS, Zughaier SM, Ziegler TR, Tangpricha V: Vitamin d deficiency is associated with anaemia among african americans in a us cohort. Br J Nutr 2015;113:1732-1740.

-12 Atkinson MA, Melamed ML, Kumar J, Roy CN, Miller ER, 3rd, Furth SL, Fadrowski JJ: Vitamin d, race, and risk for anemia in children. J Pediatr 2014;164:153-158 e151.

13 Jin HJ, Lee JH, Kim MK: The prevalence of vitamin d deficiency in iron-deficient and normal children under the age of 24 months. Blood Res 2013;48:40-45.

14 Perlstein TS, Pande R, Berliner N, Vanasse GJ: Prevalence of 25-hydroxyvitamin d deficiency in subgroups of elderly persons with anemia: Association with anemia of inflammation. Blood 2011;117:2800-2806.

15 Shin JY, Shim JY: Low vitamin d levels increase anemia risk in korean women. Clin Chim Acta 2013;421:177-180.

16 Lac PT, Choi K, Liu IA, Meguerditchian S, Rasgon SA, Sim JJ: The effects of changing vitamin d levels on anemia in chronic kidney disease patients: A retrospective cohort review. Clin Nephrol 2010;74:25-32.

17 Wen J, Hong Q, Zhu L, Xu P, Fu Z, Cui X, You L, Wang X, Wu T, Ding H, Dai Y, Ji C, Guo X: Association of maternal serum 25-hydroxyvitamin $d$ concentrations in second and third trimester with risk of gestational diabetes and other pregnancy outcomes. Int J Obes (Lond) 2017;41:489-496.

18 Liu T, Zhong S, Liu L, Liu S, Li X, Zhou T, Zhang J: Vitamin d deficiency and the risk of anemia: A metaanalysis of observational studies. Ren Fail 2015;37:929-934.

19 Thomas CE, Guillet R, Queenan RA, Cooper EM, Kent TR, Pressman EK, Vermeylen FM, Roberson MS, O'Brien KO: Vitamin d status is inversely associated with anemia and serum erythropoietin during pregnancy. Am J Clin Nutr 2015;102:1088-1095.

20 Bener A, Al-Hamaq AO, Saleh NM: Association between vitamin d insufficiency and adverse pregnancy outcome: Global comparisons. Int J Womens Health 2013;5:523-531.

21 Alon DB, Chaimovitz C, Dvilansky A, Lugassy G, Douvdevani A, Shany S, Nathan I: Novel role of 1, 25(oh)(2) $\mathrm{d}(3)$ in induction of erythroid progenitor cell proliferation. Exp Hematol 2002;30:403-409.

-22 Aucella F, Scalzulli RP, Gatta G, Vigilante M, Carella AM, Stallone C: Calcitriol increases burst-forming unit-erythroid proliferation in chronic renal failure. A synergistic effect with r-huepo. Nephron Clin Pract 2003;95:c121-127.

23 Saab G, Young DO, Gincherman Y, Giles K, Norwood K, Coyne DW: Prevalence of vitamin d deficiency and the safety and effectiveness of monthly ergocalciferol in hemodialysis patients. Nephron Clin Pract 2007;105:c132-138.

24 Bikle D: Nonclassic actions of vitamin d. J Clin Endocrinol Metab 2009;94:26-34.

-25 Zaritsky J, Young B, Wang HJ, Westerman M, Olbina G, Nemeth E, Ganz T, Rivera S, Nissenson AR, Salusky IB: Hepcidin--a potential novel biomarker for iron status in chronic kidney disease. Clin J Am Soc Nephrol 2009;4:1051-1056.

26 Ganz T, Nemeth E: Hepcidin and iron homeostasis. Biochim Biophys Acta 2012;1823:1434-1443.

27 Carvalho C, Isakova T, Collerone G, Olbina G, Wolf M, Westerman M, Gutierrez OM: Hepcidin and disordered mineral metabolism in chronic kidney disease. Clin Nephrol 2011;76:90-98. 